\title{
$L_{p}$-MIXED INTERSECTION BODIES
}

\section{DEYAN ZHANG}

Abstract. In this paper, we prove a dual Bergstrom type inequality for $q$-dual mixed volumes. Furthermore, we introduce the $L_{p}$-mixed intersection bodies for any real number $p \neq 0$, and establish some interesting inequalities for $L_{p}$-mixed intersection bodies involving a Minkowski type inequality and three Brunn-Minkowski type inequalities.

Mathematics subject classification (2010): 52A38, 52A40.

Keywords and phrases: Star bodies, $q$-dual mixed volumes, $L_{p}$-mixed intersection bodies.

\section{REFERENCES}

[1] R. Bellman, Notes on matrix theory -Iv: an inequality due to Bergstrom, Am. Math. Mon., 62 (1955), 172-173.

[2] H. Bergstrom, A triangle inequality for matrices, In: Den Elfte Skandinaviski Matematikerkongress, Trondheim, 1949, John Grundt Tanums Forlag, Oslo, 1952.

[3] K. J. BÖRÖCZKY, E. LUTWAK, D. YANG AND G. Y. ZHANG, The log-Brunn-Minkowski inequality, Adv. Math., 231 (2012), 1974-1997.

[4] H. Busemann, Volume in terms of concurrent cross-sections, Pacific J. Math., 3 (1953), 1-12.

[5] S. CAMPI, Stability estimates for star bodies in terms of their intersection bodies, Mathematika, 45 (1998), 287-303.

[6] S. CAMPI, Convex intersection bodies in three and four dimensions, Mathematika, 46 (1999), 15-27.

[7] H. FAllert, P. GoOdey AND W. WeIL, Spherical projections and centrally symmetric sets, Adv. Math., 129 (1997), 301-322.

[8] K. FAn, Some inequalities concerning positive-definite Hermitian matrices, Proc. Camb. Philos. Soc., 51 (1955), 414-421.

[9] W. J. FIREY, p-means of convex bodies, Math. Scand., 10 (1962), 17-24.

[10] M. Fradelizi, A. Giannopoulos And M. Meyer, Some inequalities about mixed volumes, Isr. J. Math., 135 (2003), 157-179.

[11] R. J. GARDNeR, Intersection bodies and the Busemann-Petty problem, Trans. Amer. Math. Soc., 342 (1994), 435-445.

[12] R. J. GARDNER, A positive answer to the Busemann-Petty problem in three dimensions, Ann. Math., 140 (1994), 435-447.

[13] R. J. Gardner, D. Hug And W. Weil, Operations between sets in geometry, J. Eur. Math. Soc., 15 (2013), 2297-2352.

[14] P. Goodey, E. LutwaK And W. WeIL, Functional analytic characterizations of classes of convex bodies, Math. Z., 222 (1996), 363-381.

[15] P. Goodey AND W. WeIL, Intersection bodies and ellipsoids, Mathematika, 42 (1995), 295-304.

[16] E. GRinberg And G. Y. Zhang, Convolutions, transforms, and convex bodies, Proc. London Math. Soc., 78 (1999), 77-115.

[17] C. Haberl And M. Ludwig, A characterization of $L_{p}$ intersection bodies, Int. Math. Res. Not., 17 (2006), Art ID 10548, 29 pages.

[18] A. KOLDOBSKY, Intersection bodies, positive definite distributions, and the Busemann-Petty problem, Amer. J. Math., 120 (1998), 827-840.

[19] A. Koldobs Ky, Second derivative test for intersection bodies, Adv. Math., 136 (1998), 15-25.

[20] A. KoldobSKy, Intersection bodies in $\mathbb{R}^{4}$, Adv. Math., 136 (1998), 1-14. 
[21] A. Koldobsky, Intersection bodies and the Busemann-Petty problem, C. R. Acad. Sci. Paris S. I Math., 325 (1997), 1181-1186.

[22] A. Koldobsky, A functional analytic approach to intersection bodies, Geom. Funct. Anal., 10 (2000), 1507-1526.

[23] M. Ludwig, Intersection bodies and valuations, Amer. J. Math., 128 (2006), 1409-1428.

[24] E. Lutwak, Dual mixed volumes, Pacific J. Math., 58 (1975), 531-538.

[25] E. LutwaK, Mixed projection inequalities, Trans. Amer. Math. Soc., 287 (1985), 91-105.

[26] E. LutwaK, Volumes of mixed bodies, Trans. Amer. Math. Soc., 294 (1986), 487-500.

[27] E. LuTwAK, Intersection bodies and dual mixed volumes, Adv. Math., 71 (1988), 232-261.

[28] E. LuTwAK, Inequalities for mixed projection bodies, Trans. Amer. Math. Soc., 339 (1993), 901-916.

[29] M. Moszyńska, Quotient star bodies, intersection bodies, and star duality, J. Math. Anal. Appl., 232 (1999), 45-60.

[30] R. SChneIDER, Convex Bodies: The Brunn-Minkowski Theory, second expanded edition, Cambridge University Press, Cambridge, 2014.

[31] G. Y. ZHANG, Intersection bodies and polytopes, Mathematika, 46 (1999), 29-34.

[32] G. Y. ZhAng, A positive solution to the Busemann-Petty problem in $\mathbb{R}^{4}$, Ann. Math., 149 (1999), 535-543.

[33] C. J. ZHAO, $L_{p}$-mixed intersection bodies, Science in China Series A: Mathematics Dec., 51 (2008), $2172-2188$.

[34] C. J. Zhao And W. S. Cheung, $L_{p}$-mixed intersection bodies and star duality, Proc. Indian Acad. Sci. (Math. Sci), 120 (2010), 429-440. 